\title{
Determinants of Computer Vision Syndrome among Bank Employees in Minia City, Egypt
}

\author{
Nashaat N. Kamal ${ }^{1}$, and Ayman S. Abd El-Mageed ${ }^{2}$ \\ 1 Public Health, ${ }^{2}$ Occupational Medicine Faculty of Medicine, Minia University, Egypt, \\ Faculty of Medicine, Minia University, Egypt
}

Received: January, 2016 Accepted: March, 2016

\begin{abstract}
Background: There is growing body of evidence that use of computers can adversely affect the visual health. Objective: To study the frequency and risk factors of computer vision syndrome (CVS) among bank employees in Minia. Method: Community-based crosssectional study of 218 bank employees who work on computer for at least one year preceding the date of the study. Two hundred and eighteen (218) computer workers working in seven different banks were selected randomly. Subjects were asked to fill a pre-tested structured questionnaire, and other relevant information was obtained by personal interview and inspection of workstation. Results: Among the 218 subjects studied, $85.2 \%$ suffer from ocular complaints. Headache (24.8\%), eye strain (20.2\%), diminution of vision (16.9\%) were the most common ocular complaints and they have significant associations in subjects working for more than 4 hours, keeping a distance less than 20 inch from the computer, who do not take breaks and do not adjust the brightness. Conclusions: Prevalence of CVS was noted to be quite high among bank employee. Headache, eye strain, diminution of vision, blurred vision, double vision, itching and burning sensation were the factors independently associated with CVS.
\end{abstract}

Keywords: computer vision syndrome, bank employees, prevalence, Minia

Corresponding author: Nashaat N. Kamal e-mail: nashaatnabilkamal@yahoo.com

\section{Introduction}

The use of computers was one of the commonest office tools in all work fieldsand computers had become a $21^{\text {st }}$ century necessity. Extensive use of computers will result in computer vision syndrome (CVS), and the prevalence is increased dramatically ${ }^{(1)}$ American Optometric Association (AOA) defines computer vision syndrome (CVS) as a "Complex of eye and vision problems related to near work, which are experienced during or related to computer use". Computer operators very frequently report ocular disorders, the so-called computer vision syndrome (tired eyes, irritation, redness, eye strain, blurred vision and double vision). ${ }^{2}$

CVS was defined as the combination of eye and vision problems associated with the use of computers. ${ }^{3}$ Symptoms of CVS include eye strain, headache, blurred vision and neck or shoulder pain that generally increase in severity with the amount of video display terminal (VDT) use. $^{4}$

The prevalence of CVS ranges from (64\% to $90 \%$ ) among computer users. ${ }^{5}$ Approximately, about 60 million people suffer from CVS globally and a million of 
new cases of CVS occur each year. ${ }^{6}$ In Egypt, Eye strain $(72.4 \%)$ and headache $(64.4 \%)$ were the commonest reported CVS symptoms. ${ }^{7}$

Appropriate setup and use of the computer workstation can help to reduce these aches and pains as chair adjustment, proper placement of monitor and documents, glare elimination and using of alternative keyboards. ${ }^{8}$

Very little researches have been performed to document the effects of computer use on CVS among Egyptian users; hence, this study was designed to assess the prevalence of CVS among computer-using bank employees in Minia city during the period from January to June 2016.

\section{Methods}

Study design and sample: A community based cross-sectional study was conducted among computer-using bank employees in Minia city, Egypt. Minia city is located $240 \mathrm{~km}$ south from the national capital, Cairo city. Four banks had been chosen randomly, from public and private banks. All Bank employees who used computer for at least one year preceding the date of the study were included in the study except those who were absent at the period of the study and those who did not consent to participate in the study (only 8 persons, so the response rate was 96.3\%). The institutional ethical review board approved the study. The participants were surveyed using a structured questionnaire, which included the basic demographic profile, hours of computer use per day, frequency of break while working on computers, brightness adjustment and any ocular complaints as eye strain, headache, watering, blurred vision, double vision, redness, burning, itching and diminution of vision for distance.The questionnaire derived from a previous published study to evaluate the factors contributing to Ocular complaints in computer users in Teerthanker Mahaveer University, India. ${ }^{9}$ All bank employees who used computer for at least one year preceding the date of study were included. Employees having ocular problems prior to computer use or due to another cause as accidents or a previous operation were excluded.

Statistical analysis: Data were analyzed using SPSS, version 22. Quantitative data were presented by mean and standard deviation, while qualitative data were presented by frequency distribution. Chisquare test, Fisher's exact, $\mathrm{z}$ test used for proportions. Student t-test was used to compare two means. Spearman's correlation used to correlate between qualitative data and binary logistic regression also used $\mathrm{p}$ value $<0.05$ was considered significant.

Ethical considerations: This study was approved by the research ethics committee of the Minia University. All procedures performed were in accordance with the ethical standards of the institutional research ethics committee. A written consent was taken after explaining the nature, purpose and uses of the data from each participant.

\section{Results}

The age of participants ranges from (2359) years with a mean of $(38.9 \pm 9.9)$, the period of working in current job ranges from (1-38) years with a mean of (16.5 \pm $9.8),(65.6 \%)$ are males and $(34.4 \%)$ are females. From all the studied participants, $(75.9 \%)$ have an urban residence, as shown in table (1).

The most frequent occurring complaints among participants are headache $(24.8 \%)$, eye strain $(20.2 \%)$, diminution of vision (16.9\%), blurred vision (7.3\%), double vision (6.1\%),itching (5.5\%), followed by burning sensation $(3.3 \%)$. 
Table (1) Socio-demographic characteristics of the studied subjects

\begin{tabular}{|l|r|}
\hline $\begin{array}{c}\text { Socio-demographic } \\
\text { characteristics }\end{array}$ & Mean \pm SD (Range) \\
\hline Age (years) & $38.9 \pm 9.9(23-59)$ \\
\hline $\begin{array}{l}\text { Period of working in } \\
\text { current job (years) }\end{array}$ & $16.5 \pm 9.8(1-38)$ \\
\hline Gender: N (\%) & $143(65.6)$ \\
Male & $75(34.4)$ \\
Female & $165(75.9)$ \\
\hline Residence: N (\%) & $53(24.3)$ \\
Urban & \\
Rural &
\end{tabular}

The ocular complaints are more and have significant associations in subjects working for more than 4 hours, also ocular complaints are more and have significant association when subjects keeping a distance less than 20 inch from the computer, it also observed that who do not taking breaks and not adjusting the brightness have significant associations with ocular complaints ( Table 3 ).

Table (4) shows that there is a moderate correlation between the duration of computer use and ocular complaints and this correlation is statistically significant $(\mathrm{r}$ $=0.49$ and $\mathrm{p}=0.0001$ ), this table also shows that there is a negative fair correlation between the distance from the screen and ocular complaints $(r=-0.36$ and $\mathrm{p}=0.03$ ) this association is statistically significant and there is a moderate positive correlation between not taking breaks and ocular complaints and this correlation is statistically significant $(\mathrm{r}$ $=0.52$ and $\mathrm{p}=0.001$ ).

As shown in table (5) higher odds ratio for the level of the screen of the computer and the duration of computer use $(\mathrm{OR}=3.8$ and 3.2 respectively) are observed.

\section{Discussion}

This study is a descriptive cross-sectional study conducted among computer-using bank employees in Minia cityto identify the prevalence rate of ocular disorders associated with computer use. The study included 218 computer-using bank employees and it was done during the period from January to June 2016.

This study showed that $(85.2 \%)$ from participants suffer from ocular complaints which approximate what reported in a previous study in Spain ${ }^{(10)}$ which found the prevalence was as high as $(68.5 \%)$ which was also higher than that reported ${ }^{11}$ in a study which was done in India and found the prevalence rate of ocular complaints was $(46.3 \%)$ among the computer operators and another study which was performed on 385 bank workers at Italy and reported the prevalence of such ocular complaints was (31.9\%). ${ }^{12}$

Table (2) Ocular complaints reported by the studied subjects

\begin{tabular}{|l|r|}
\hline \multicolumn{1}{|c|}{ Ocular complaints } & N $(\%)$ \\
\hline Headache & $54(24.8)$ \\
\hline Eye strain & $44(20.2)$ \\
\hline Diminution of vision & $37(16.9)$ \\
\hline Blurred vision & $16(7.3)$ \\
\hline Double vision & $13(6.1)$ \\
\hline Itching & $12(5.5)$ \\
\hline Burning & $9(4.1)$ \\
\hline No complaints & $33(15.1)$ \\
\hline
\end{tabular}

This study showed that the ocular complaints arranged in the following descending order: headache (25.3\%), eye strain $(22 \%)$, diminution of vision $(17.6 \%)$, blurred vision $(6.6 \%)$, itching (5.5\%), double vision (4.9\%) and burning sensation (3.3\%)which approximate what reported in previous study in Nigeria (13) which found that the ocular complaints arranged in the following descending order headache $(30.9 \%)$, eye strain $(30.9 \%)$, double vision (12.9\%), watery eyes $(10.8 \%)$ blurred vision (10.1\%) and redness $(4.3 \%)$, but was not in agreement with a study ${ }^{9}$ which studied CVS on two hundred computer operators working in different institutes offices in Moradabad 
Table (3) Association of various possible risk factors with ocular complaints reported by the studied subjects

\begin{tabular}{|c|c|c|c|}
\hline \multirow{2}{*}{$\begin{array}{c}\text { Risk } \\
\text { factors }\end{array}$} & \multicolumn{2}{|c|}{ Ocular complaints } & \multirow{2}{*}{$\begin{array}{l}\chi^{2}(\mathrm{DF})^{*} \\
\text { P- value }\end{array}$} \\
\hline & $\begin{array}{c}\text { No } \\
\mathbf{N}(\%) \\
\end{array}$ & $\begin{array}{c}\text { Yes } \\
\mathbf{N}(\%)\end{array}$ & \\
\hline $\begin{array}{l}\text { Duration of } \\
\text { computer } \\
\text { use } \\
\bullet<2 \text { hours } \\
\bullet 2-4 \text { hours } \\
\bullet>4 \text { hours }\end{array}$ & $\begin{array}{r}6(20.7) \\
23(35.9) \\
12(9.6)\end{array}$ & $\begin{array}{r}23(79.3) \\
41(64.1) \\
113(90.4)\end{array}$ & $\begin{array}{l}19.3(2) \\
<0.001 *\end{array}$ \\
\hline $\begin{array}{l}\text { Distance } \\
\text { from } \\
\text { computer } \\
\text { - }<20 \text { inch } \\
\text { - } 20-24 \text { inch } \\
\text { - }>24 \text { inch }\end{array}$ & $\begin{array}{r}16(10.8) \\
21(36.2) \\
2(16.7)\end{array}$ & $\begin{array}{r}132(89.2) \\
37(63.8) \\
10(83.3)\end{array}$ & $\begin{array}{l}18.3(2) \\
<0.001 *\end{array}$ \\
\hline $\begin{array}{l}\text { Level of top } \\
\text { of screen } \\
\text { - At eye } \\
\text { level } \\
\text { - Below eye } \\
\text { level } \\
\text { - Above eye } \\
\text { level } \\
\end{array}$ & $\begin{array}{l}22(18.2) \\
9(19.6) \\
9(16.9)\end{array}$ & $\begin{array}{l}99(81.2) \\
37(80.4) \\
44(83.1)\end{array}$ & $\begin{array}{l}0.1(2) \\
0.9\end{array}$ \\
\hline $\begin{array}{l}\text { Taking } \\
\text { breaks } \\
\text { - Yes } \\
\text { - No }\end{array}$ & $\begin{array}{l}52(54.2) \\
3(2.5)\end{array}$ & $\begin{array}{r}44(45.8) \\
119(97.5)\end{array}$ & $\begin{array}{l}76.14(1) \\
<0.001 *\end{array}$ \\
\hline $\begin{array}{l}\text { Brightness } \\
\text { adjustment } \\
\text { - Yes } \\
\text { - No }\end{array}$ & $\begin{array}{l}12(23.5) \\
28(16.8)\end{array}$ & $\begin{array}{r}39(76.5) \\
139(83.2)\end{array}$ & $\begin{array}{l}1.19 \\
0.02 *\end{array}$ \\
\hline
\end{tabular}

*p value was calculated by using chi square test

and found that the major ocular complaints which were reported arranged in the following descending order were eyestrain $(53 \%)$, headache $(42.66 \%)$, diminution of vision for distance (34\%), watering, redness, itching, burning and double vision.

Also Sen and Richardson found that headache $(61 \%)$ and redness $(46 \%)$ were the commonest ocular complaints reported in their study (14). Similarly eye strain (97.8\%) and headache $(82.1 \%)$ were the commonest ocular complaints reported in another Indian study (15). Opposite to this Shrestha et al., found that headache
$(13.3 \%)$ and tired eye (12.5\%) were the commonest ocular complaints reported in a previous study. ${ }^{16}$

Table (4) Correlation between various possible risk factors and ocular complaint reported by the studied subjects

\begin{tabular}{|l|c|c|}
\hline \multirow{2}{*}{ Risk factors } & \multicolumn{2}{c|}{$\begin{array}{c}\text { Ocular complaints } \\
\text { Spearman's rho }\end{array}$} \\
\cline { 2 - 3 } of & r & P value \\
\hline $\begin{array}{l}\text { Duration } \\
\text { computer use }\end{array}$ & 0.49 & $0.001^{*}$ \\
\hline Level of the screen & 0.24 & 0.12 \\
\hline $\begin{array}{l}\text { Distance from the } \\
\text { screen }\end{array}$ & -0.36 & $0.03^{*}$ \\
\hline Beaks & 0.52 & $0.001^{*}$ \\
\hline
\end{tabular}

This study showed that ocular complaints are more among males (51.6\%) than females $(48.4 \% \%)$ and this difference is found to be statistically significant, females maintaining a proper distance from the screen than males, females using computer for longer period than males which is in agreement with a previous study. ${ }^{17}$ However, another study found that the female subjects used computers for lesser time periods than the males, as well as, most of them maintained a proper viewing distance from the computer screen, but they did not find any significant association with the age and gender of the subjects with these complaints. ${ }^{9}$ Such ocular complaints were correlated with the age and gender of the subjects in one such study. ${ }^{12}$

This study showed a significant difference in ocular complaints and duration of computer use daily as the prevalence of ocular complaints higher in subjects use computers for more than 4 hours daily which in agreement with a previous study which reported that the prevalence of the visual symptoms was significantly higher in the individuals who spent more than 4 hours daily, working on video display 
Table (5): Multiple logistic regression analysis of risk factors predicting occurrence of ocular complaints among studied subjects

\begin{tabular}{|l|l|l|l|}
\hline Risk factor & OR & 95\% CI & P \\
\hline Level of the screen & 3.875 & $0.608-35.94$ & $0.01^{*}$ \\
\hline Duration of computer use & 3.220 & $0.248-38.41$ & $0.03^{*}$ \\
\hline Age & 1.025 & $0.003-0.177$ & $0.001^{*}$ \\
\hline Distance from the screen & 0.034 & $0.002-0.552$ & $0.01^{*}$ \\
\hline Brightness adjustment & 0.028 & $0.005-0.171$ & $0.001^{*}$ \\
\hline
\end{tabular}

N.B. the dependant variable is ocular complaints. OR: odds ratio; CI: confidence interval. $\mathrm{R}^{2}=0.54$

terminals ${ }^{18}$ while another study found a significant difference in such complaints and in the daily hours of the visual display terminal work between the workers who worked less than 6 hours daily and those who worked more than 6 hours daily ${ }^{(19)}$, moreover another study revealed that the ocular complaints were reported more by the subjects who used computers for more than 6 hours a day, of which eye strain $(53.8 \%)$,itching $(47.6 \%)$ and burning $(66.7 \%)$ were statistically significant in these subjects. ${ }^{9}$

This study showed that ocular complaints havea fair positive correlation with duration of computer use and this correlation is statistically significant which in agreement with 2 such studies which also showed that the duration of the computer work was directly related to the eye symptoms, and that a longer duration tended to result in long-lasting complaints which persisted even after the Visual Display Terminal (VDT) work was finished ${ }^{17}$ while it is not in agreement of another study. ${ }^{12}$

The viewing distance of the computer is also an important risk factor for the development of ocular complaints. The closer the VDT is to the eyes, the harder the eyes have to work to accommodate with it. These problems can be explained as that close distance causes an excess accommodation, thus leading to overworking of the ciliary muscles of the eye, therefore inducing the symptoms of
CVS as eye fatigue and headache. Working with monitors that make the users concentrate on the VDT, decreases the speed of blinking and the eye exposure to the free air increases, thereby causing redness burning, tiredness and eyestrain ${ }^{(9)}$. This study showed that there is a significant associationof ocular complaints in the subjects who did not maintain a proper distance of 20-24 inches from the computer which in agreement with a previous study which found a significant association of ocular complaints in the subjects who did not maintain a proper distance of 20-24 inches from the computer and eye strain and headache ${ }^{9}$ while another study showed that the ocular complaints was less in the subjects whose viewing distance was more than $30 \mathrm{~cm} \mathrm{(12}$ inches) and that it was the highest when the viewing distance was less than $30 \mathrm{~cm}$ (12 inches), which was statistically

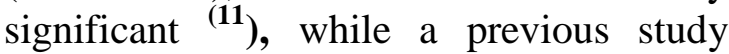
recommended a viewing distance of 50- 70 $\mathrm{cm}^{20}$

This study showed that the ocular complaints were less when the subjects maintained the top of the screen level below the eyes which in agreement with a study which found that the complaints were less when the subjects maintained the top of the screen level below the eyes, but a significant association was found only for eyestrain. ${ }^{9}$ Similar results were found in two such studies and therefore a downward gaze was recommended so as to 
work comfortably on a VDT. ${ }^{20,21}$ Other studies have reported increased the eye discomfort symptoms when the computer operators kept the terminal at about the eye level rather than below the eye level. ${ }^{22}$ Also a study found that high screens result in greater eyestrain than the low screens and found that the change from a greater to a lesser viewing distance produced a larger increase in the eyestrain when the VDTs were at eye level. ${ }^{23}$

This study showed that there is a statistically significant difference between ocular complaints and not taking breaks as ocular complaints more in individuals didn't take frequent breaks which in agreement with a study ${ }^{24}$ which found that taking frequent breaks while using the computer increases the efficiency and that it relaxes the accommodative system also it was found in a study that eyestrain and burning of the eyes were found to be significantly associated with the subjects who did not take breaks during the computer use $^{9}$, while in another study ${ }^{25}$ it was found that frequent work breaks (at least once per hour) have to be taken in order to prevent the eye strain which is associated by prolonged eye work, as was recommended in one of the studies. It also helps the muscles of the eye to relax, thus decreasing the eye fatigue and headache.

\section{Conclusion}

More than three-fourths of computer-using bank employees suffered from CVS with the most experienced symptoms of headache, eye strain, diminution of vision, blurred vision, double vision, itching and burning sensation were the factors independently associated with CVS.To avoid these computer-related vision problems, it is better to give eye health education for computer users on how touse computers, and the manifestations, treatment options and prevention strategies of CVS.

\section{Acknowledgment}

The authors would like to thank all participant and the persons who helped us in conduction of the research.

Funding: This study was supported by Minia University, Egypt,

Conflict of interest: None declared

\section{References}

1. Anshel J, editor.Visual Ergonomics Handbook. New York, NY: Taylor and Francis; 2005.

2. Poonam M, and Rajagopala M.A clinical study on "Computer vision syndrome" and its management with Triphala eye drops and SaptamritaLauha.Ayu. 2010; 31(2): 236-239.

3. Rosenfield M. Computer vision syndrome: A review of ocular causes and potential treatments. Ophthalmic Physiol Opt. 2011;31:502-15.

4. American Optometric Association (AOA).The effects of computer use on eye health and vision. 1995. [Last accessed on 2013 June 15]. http://www.aoa.org/patientsand-public/caring-for-your-vision/protectingyour-vision/computer-vision-syndrome

5. Hayes JR, Sheedy JE, Stelmack JA, Heaney CA. Computer use, symptoms, and quality of life. Optom Vis Sci. 2007;84:738-44 6. Sen A, Richardson S.A study of computer-related upper limb discomfort and computer vision syndrome.J Hum Ergol (Tokyo) 2007;36:45-50

7. Gabal M, Abd El-Aziz K, Mostafa N, and Almadani T. Computer Vision Syndrome and Musculoskeletal disorders among call center workers of a private company. The Egyptian Journal of community medicine. 2015; 34(4): 51:57.

8. LadouJ, Balmes j, Benowitz N, Blanc P, Chowdhury M, Christian j. Current Occupational and Environmental medicine Fourth edition, San Fransesco. 2007;p:159161. 
9. Agarwal S, Goel D, Sharma A. Evaluation of the factors which contribute to the ocular complaints in computer users. J Clin Diagn Res. 2013; 7(2): 331-335.

10. Sanchez-Roman FR, Perez-Lucio C, Juarez-Ruiz C, Velez-Zamora NM, JimenezVillarruel M. Risk factors for asthenopia among computer terminal operators.SaludPublica Mex.1996; 38(3):189196.

11. Bhanderi DJ, Choudhary S, Doshi VG. A community-based study of asthenopia in computer operators.Indian J. Opthalmol. 2008; 56 (1):51-55.

12. Mocci F, Serra A, Corrias GA. Psychological factors and visual fatigue in working with video display terminals .Occup Environ Med. 2001; 58(4):267-271.

13. Akinbinu RT, Mashalla YJ. .Impact of computer technology on health: Computer vision syndrome (CVS). Academic Journals.2014; 5(3): 20-30.

14. Sen A, Richardson S. A study of computer-related upper limb discomfort and computer vision syndrome.J Hum Ergol (Tokyo). 2007; 36(2):45-50

15. Bali J, Navin N, Thakur BR. Computer Vision Syndrome: a study of the knowledge, attitudes and practices in Indian ophthalmologists.Indian J. Ophthalmol. 2007; 55:289-293.

16. Shrestha GS, Mohamed FN, Shah DN. Visual problems among video display terminal (VDT) users in Nepal. J. Optom. 2011; 4(2):56-62.

17. Logaraj M, Madhupriya V, and Hegde SK. Computer Vision Syndrome and Associated Factors Among Medical and
Engineering Students in Chennai. Ann Med Health Sci Res. 2014; 4(2): 179-185.

18. Rossignol AM, Morse EP, Summers VM, Pagnotto LD . Visual display terminal use and reported health symptoms among Massachusetts clerical worker. J. Occup. Med. 1987; 29:112-118.

19. Hanne W, Brewitt H, AugenklinikRechts DI, Munchen TU. Changes in visual function caused by work at a data display terminal.Ophthalmologe. 1994; 91:107-112.

20. 20. Taptagapom S, Sotoyama M, Saito S, Suzuki T , Saito S. Visual comfort in VDT workstation design. J. Hum. Ergol. 1995;24(1):84-88.

21. QuarantaLeoni FM, Molle F, Scavino G, Dickmann A. Identification of the preferential gaze position through elevation of visual fatigue in a selected group of VDU operators: A preliminary study. Doc Ophthalmol. 1994; 87(2):189-197.

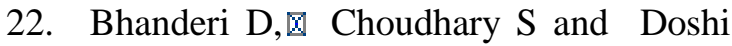
V. A community-based study of asthenopia in computer operators.Indian J Ophthalmol. 2008; 56(1): 51-55.

23. Jaschinski W, Heuer H, Kylian H (1998). Preferred position of visual displays relative to the eyes: A field study of visual strain and individual differences. Ergonomics 41(7): 1034-1049.

24. Fenety A, Walker JM .Short term effects of workstation exercise on musculoskeletal discomfort and postural changes in seated video display unit workers, Physical Therapy. 2002: 82(6): 578-589.

25. Levy B, Wagner G, Rest K,Weeks J. Preventing Occupational Disease and Injury. American Health Association. 2005;200. 